\title{
Sustainable Nanopozzolan Modified Cement: Characterizations and Morphology of Calcium Silicate Hydrate during Hydration
}

\author{
N. Mohamed Sutan, ${ }^{1}$ I. Yakub, ${ }^{1}$ M. S. Jaafar, ${ }^{2}$ K. A. Matori, ${ }^{2}$ and S. K. Sahari ${ }^{1}$ \\ ${ }^{1}$ Department of Civil Engineering, Department of Chemical Engineering and Energy Sustainability, and Department of Electrical and \\ Electronic Engineering, Faculty of Engineering, Universiti Malaysia Sarawak, Sarawak 94300, Malaysia \\ ${ }^{2}$ Department of Civil Engineering, Faculty of Engineering, and Department of Physics, Faculty of Science, Universiti Putra Malaysia, \\ Selangor 43400, Malaysia
}

Correspondence should be addressed to N. Mohamed Sutan; msnorsuzailina@feng.unimas.my

Received 17 December 2014; Revised 2 March 2015; Accepted 5 March 2015

Academic Editor: Anmin Zheng

Copyright ( $\odot 2015$ N. Mohamed Sutan et al. This is an open access article distributed under the Creative Commons Attribution License, which permits unrestricted use, distribution, and reproduction in any medium, provided the original work is properly cited.

\begin{abstract}
There are environmental and sustainable benefits of partially replacing cement with industrial by-products or synthetic materials in cement based products. Since microstructural behaviours of cement based products are the crucial parameters that govern their sustainability and durability, this study investigates the microstructural comparison between two different types of cement replacements as nanopozzolan modified cement (NPMC) in cement based product by focusing on the evidence of pozzolanic reactivity in corroboration with physical and mechanical properties. Characterization and morphology techniques using X-ray diffraction (XRD), Fourier transform infrared spectroscopy (FTIR), energy-dispersive X-ray spectroscopy (EDS), and scanning electron microscopy (SEM) were carried out to assess the pozzolanic reactivity of cement paste modified with the combination of nano- and micro silica as NPMC in comparison to unmodified cement paste (UCP) of 0.5 water to cement ratio (w/c). Results were then substantiated with compressive strength (CS) results as mechanical property. Results of this study showed clear evidence of pozzolanicity for all samples with varying reactivity with NPMC being the most reactive.
\end{abstract}

\section{Introduction}

As the fourth largest consumer amongst Southeast Asia's countries, Malaysia consumed 17 million tons of cement by the end of 2011 [1]. With the high demand, large scale production is needed for its satisfaction that consequently releases more carbon dioxide $\left(\mathrm{CO}_{2}\right)$ that causes greenhouse effects. Cement replacement for cement based materials is one of the options to meet the increasing sustainability, green technology demands, and requirement in construction industry since it offers two distinct benefits to the environment: it significantly reduces the amount of $\mathrm{CO}_{2}$ released into the atmosphere and minimizes massive landfill disposal. Therefore interest in cement research is moving towards finding viable whole or partial cement replacement like using industrial wastes such as microsilica (MS) and nanoscale materials such as nanosilica (NS). In addition, recently, research and development $(\mathrm{R} \& \mathrm{D})$ on cement based material is of interest to find new cement supplementary materials in nanoscale. For Malaysia, nanotechnology R\&D was started by the government in 2001 and categorized as a strategic research (SR) program under IRPA in the Eighth Malaysia Plan (8MP) which spans from 2001 to 2005 and funded by the MOSTI [2].

MS and NS have one thing in common which is that they possess a pozzolanic characteristic. Pozzolanic materials have the high potential to be a substance to replace cement due to beneficial pozzolanic reaction that can improve cement based product properties. As generally known, calcium hydroxide $(\mathrm{CH})$ or portlandite produced from the hydration process of cement will react with siliceous pozzolanic material to produce more C-S-H which is the substance that mainly contributes to strength for cement based material that can improve physical and mechanical properties such as reducing porosity and permeability. Hence, cement blended with pozzolanic material will have better strength and durability [3]. 
TABLE 1: Chemical and mineralogical composition of OPC.

\begin{tabular}{lcccccccccc}
\hline Component, \% & $\mathrm{CaO}$ & $\mathrm{SiO}_{2}$ & $\mathrm{Al}_{2} \mathrm{O}_{3}$ & $\mathrm{Fe}_{2} \mathrm{O}_{3}$ & $\mathrm{SO}_{3}$ & $\mathrm{MgO}$ & $\mathrm{Na}_{2} \mathrm{O}$ & $\mathrm{K}_{2} \mathrm{O}$ & Others & LOI \\
\hline OPC & 63.0 & 21.69 & 5.75 & 3.25 & 2.35 & 1.97 & 0.50 & 0.28 & 0.11 & 1.00 \\
\hline
\end{tabular}

Previous studies have shown that MS modified concrete was stronger and more durable compared to conventional concrete. Due to its high pozzolanicity, MS has a very high content of amorphous silicon dioxide $\left(\mathrm{SiO}_{2}\right)$ and very fine spherical particles sizes which are the main reasons for its high pozzolanic activity [4]. The rate of the pozzolanic activity is related to the surface area of pozzolan particles whereby the higher the surface area of pozzolan particle is or the finer the particle is, the more reactive it would be [5]. Hence, the research and development for cement based material is of interest to find new cement supplementary material which has a particle size of nanoscale $\left(10^{-9} \mathrm{~m}\right)$. Incorporation of nanomaterials in cement and concrete production can lead to major improvement in the civil infrastructure because durability and sustainability of cement based product are determined by its microstructural mass transfer in nanoscale [6].

Previous studies have shown that MS modified concrete was stronger and more durable compared to conventional concrete. Due to its high pozzolanicity, MS has a very high content of amorphous silicon dioxide $\left(\mathrm{SiO}_{2}\right)$ and very fine spherical particles sizes which are the main reasons for its high pozzolanic activity [4]. Meanwhile NS is a new pozzolanic material that contains high percentage of silica with up to $99 \%$ purities and with small particle size in nanometer range. It is expected to have better performance due to the small particle size and high content of silica components [7-11]. Besides that, NS also acts as nuclei for cement phase and promotes cement hydration with its high pozzolanic reactivity, as nanoreinforcement and filler densifying the microstructure, leading to reducing porosity from a more compact and denser microstructure [12].

However there are no comparative studies on the potential performance of combination of MS and NS pozzolanic materials used as nanopozzolan modified cement (NPMC) in cement based products. Hypothetically, NPMC will produce a higher performance cement based product in terms of strength and durability due to their fineness and highly reactive pozzolanic properties. This study is an attempt to explore in that direction. Pozzolanic reactivity of MS, NS, and NPMC pastes was investigated and compared to unmodified cement paste (UCP). The efforts to investigate the potential usage of such nonconventional material which is typically of local or regional origin in cement based products will get a boost if there are systematic and comprehensive studies to quantify and characterize the performance of cement based products containing such materials and will contribute positively to waste management challenge.

\section{Materials and Methods}

2.1. Materials. Waste material and nanomaterial used as cement replacements in nanopozzolan modified cement
(NPMC) were microsilica from Grace Construction Sdn. Bhd. with $94.5 \% \mathrm{SiO}_{2}$ and Sigma-Aldrich silicon dioxide nanopowder (CAS 7631-86-9) of 10-20 nm particle size (BET) with $99.5 \% \mathrm{SiO}_{2}$. Cement used was ordinary Portland cement (OPC) (ASTM Type 1 recognized by ASTM C150) manufactured by Cahaya Mata Sarawak Cement Sdn. Bhd. (CMS) and it exceeds the quality requirements specified in the Malaysian Standard MS 522: Part 1: 1989 Specifications for OPC. The chemical composition of the OPC is given in Table 1.

2.2. Sample Preparation, Characterization by Using XRD, FTIR, and EDS, and Morphology Using SEM Techniques. The mix proportion for cement paste was set at 0.5 water to cement ratio $(\mathrm{w} / \mathrm{c})$ for all specimens that were casted into Universal Container $30 \mathrm{~mL}$, diameter $28 \times 85 \mathrm{~mm}$ for XRD, EDS, and SEM. All specimens were cured in the concrete laboratory at Universiti Malaysia Sarawak at daily room temperature $(T)$ and relative humidity $(\mathrm{RH})$ in the range of $18-28^{\circ} \mathrm{C}$ and $65-90 \%$, respectively. The fine powder (passing $75 \mu \mathrm{m}$ ) and polished small samples were prepared and analysed using XRD, FTIR, EDS, and SEM on day 28. Ethanol was used to discontinue the hydration process of these samples. XRD analysis for all prepared samples was performed using PANalytical equipment with $\mathrm{CuK} \alpha$ radiation and $\lambda$ of $0.1546 \mathrm{~nm}$. The specifications were count step: $4 \mathrm{sec} / \mathrm{step}$, step size: 0.02 degrees, and range: 565 2 $\theta$. Shimadzu Fourier Transform Infrared Spectroscopy (FTIR) 81001 Spectrophotometer was used to perform the FTIR analysis. The spectrum measurement method applied was attenuated total reflection (ATR) method. Transmission infrared spectrum of each sample was recorded using a Fourier transform infrared spectrophotometer (IR Affinity1) in the region of 400 to $4000 \mathrm{~cm}^{-1}$ with $2.0 \mathrm{~cm}^{-1}$ resolution. The samples were scanned 20 times. SEM images and EDS analysis for all prepared small polished samples were captured by scanning electron microscope and energy-dispersive X-ray spectroscopy (JSM-6701F) supplied by JEOL Company Limited, Japan, which followed the ASTM C 1723-10 (2010) code of practice.

2.3. Sample Preparation and Mechanical Test. The mix proportion mortar was set at (cement:sand:water) $1: 1.67: 0.5(\mathrm{w} / \mathrm{c})$ for all specimens that were casted into $150 \mathrm{~mm}$ cubes for compressive strength (CS) tests. All specimens were cured in the Concrete Laboratory at Universiti Malaysia Sarawak for 7, 14, and 28 days. CS test was performed according to BS 1881-116 (1983) on $150 \mathrm{~mm}$ cubes samples. It was used to determine the maximum compressive load that a sample can carry per unit area. Compressive strength test was performed to determine the maximum compressive load that the sample can carry 


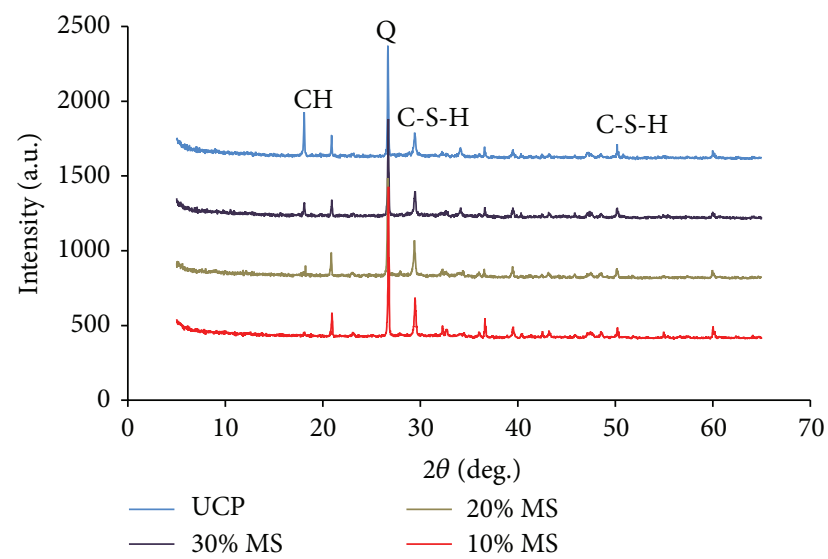

FIGURE 1: XRD pattern (CuK $\alpha$ radiation) for UCP and MS samples on day 28.

per unit area. The compressive strength is measured by using

$$
\text { compressive strength }=\frac{\text { maximum load applied }(\mathrm{N})}{\text { cross-sectional area }\left(\mathrm{mm}^{2}\right)} \text {. }
$$

\section{Results and Discussions}

\subsection{Identification of $\mathrm{CH}$ and $\mathrm{C}-\mathrm{S}-\mathrm{H}$ as Pozzolanic \\ Reaction Indication}

3.1.1. X-Ray Diffraction (XRD). The X-ray diffraction (XRD) patterns of UCP, $10 \%$ MS, $20 \%$ MS, and $30 \%$ MS on day 28 are given in Figure 1. It can be observed that crystalline $\mathrm{CH}$ (portlandite) appeared in all samples except for $30 \%$ MS sample at peaks around 18.07, 34.17, and $47.192 \theta$ while amorphous C-S-H was hardly visible but can be seen at peak around 29.54 and $50.02 \theta$ [13-16]. As for C-S-H, the intensity increased the most for $10 \%$ MS followed by $20 \%$ MS, UCP, and $30 \%$ MS showing that portlandite is consumed due to pozzolanic reaction with $\mathrm{SiO}_{2}$ producing more C-S-H.

Figure 2 shows XRD patterns for UCP, $2 \%$ NS, $3 \%$ NS, and $5 \%$ NS on day 28. Portlandite was detected in all samples at peaks around 18.07, 34.17, and $47.192 \theta$. We can observe the onset of semicrystalline Al-CSH at 29.5 and $49.52 \theta$ [13-15]. In the same figure, significant intensity of C-S- $\mathrm{H}$ can be found on sample 5\% NS [13].

Based on the results, it can be concluded that the optimum dosage for MS and NS as cement replacement in cement paste is $10 \%$ and $5 \%$, respectively. This is due to the highest intensity in C-S-H from the XRD characterization in both samples that indicated that more C-S-H were produced by pozzolanic reaction of $10 \%$ MS and $5 \%$ NS as cement replacement. Therefore NPMC of the combination of $10 \% \mathrm{MS}$ and 5\% NS was used and pozzolanic reactivity of the sample was characterized using FTIR, EDS, and SEM and further corroborated with compressive strength results.

3.1.2. Fourier Transform Infrared Spectroscopy (FTIR). Figure 3 shows that FTIR analysis focusing on pozzolanic

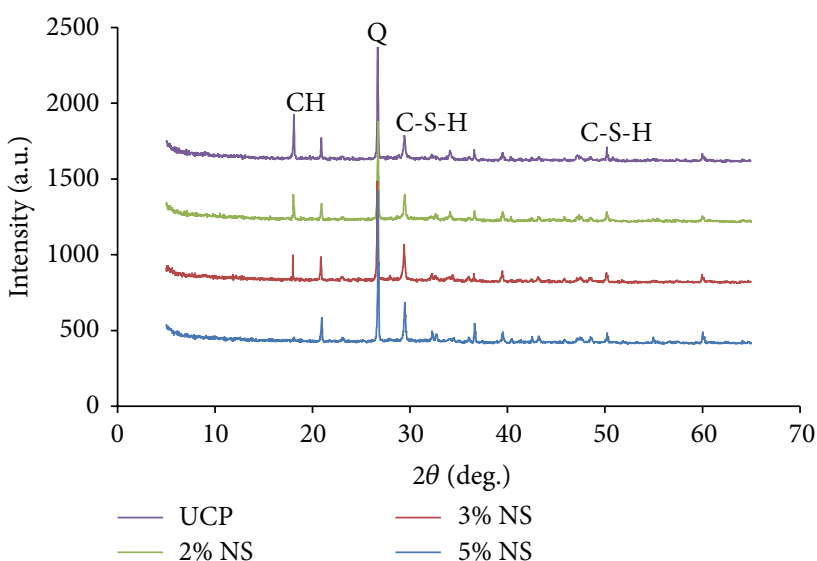

FIGURE 2: XRD pattern (CuK $\alpha$ radiation) of UCP and NS samples on day 28.

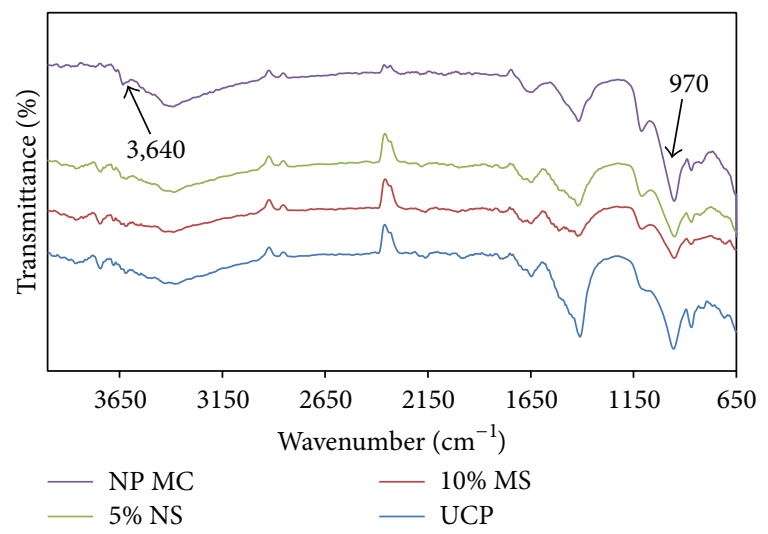

FIgURE 3: FTIR spectra for NPMC, 5\% NS, 10\% MS, and UCP on day 28.

activity was made on NPMC sample in comparison to $5 \%$ NS, $10 \%$ MS, and UCP samples. The evidence of pozzolanic activity can be found by comparing the intensity of $\mathrm{CH}$ and $\mathrm{C}-\mathrm{S}-\mathrm{H}$ band on day 28 . The infrared spectrum wave number of $\mathrm{CH}$ and C-S-H is $3,640 \mathrm{~cm}^{-1}$ and $970 \mathrm{~cm}^{-1}$, respectively $[15,16]$. Figure 3 shows (a) $\mathrm{CH}$ and (b) C-S-H band for all samples. The sharpness of the spectrum's curve indicates the intensity of the substance. It can be clearly seen that $\mathrm{C}-\mathrm{S}-\mathrm{H}$ peaks are the strongest for NPMC which confirm and substantiate the results from XRD characterization.

3.1.3. Energy-Dispersive X-Ray Spectroscopy (EDS). Ca/Si and $\mathrm{Si} / \mathrm{Ca}$ ratios obtained from EDS spectra were valid as the indication of the presence of $\mathrm{CH}$ and C-S-H. The presence of $\mathrm{C}-\mathrm{S}-\mathrm{H}$ reflected in $\mathrm{Ca} / \mathrm{Si}$ ratio. The $\mathrm{Ca} / \mathrm{Si}$ and $\mathrm{Si} / \mathrm{Ca}$ ratios for NPMC, $5 \%$ NS, $10 \%$ MS, and UCP samples on day 28 were calculated from EDS spectra and are shown in Table 2. Results indicate the presence of C-S-H and $\mathrm{CH}$ for all samples which corroborate XRD characterization results in previous sections. From a compositional point of view, C-S-H gel is often characterized by its $\mathrm{Ca} / \mathrm{Si}$ ratio, which typically ranges from 0.7 to 2.3 [17]. But the typical $\mathrm{Ca} / \mathrm{Si}$ ratio of C-S-H 


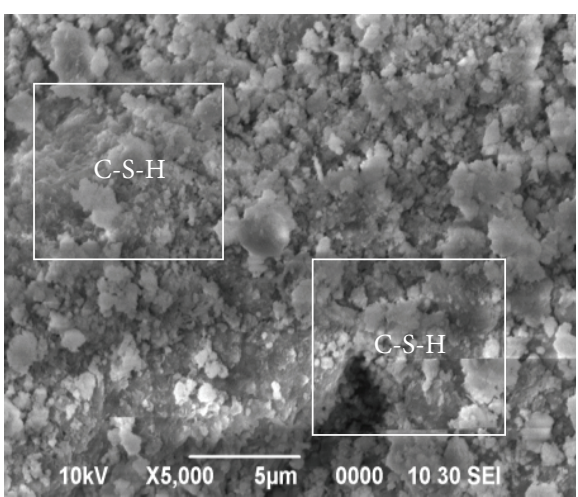

(a) NPMC

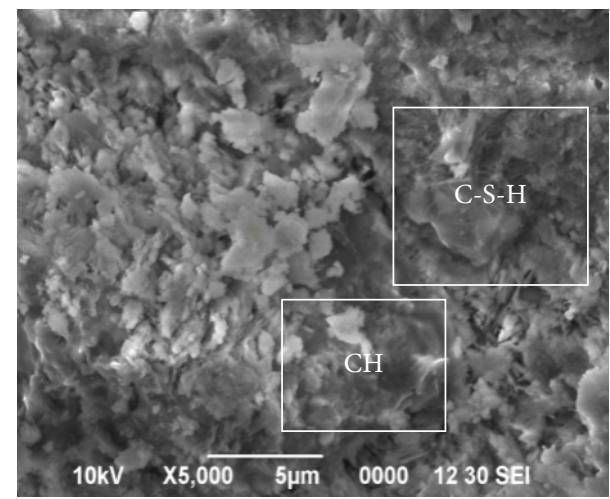

(c) $10 \% \mathrm{MS}$

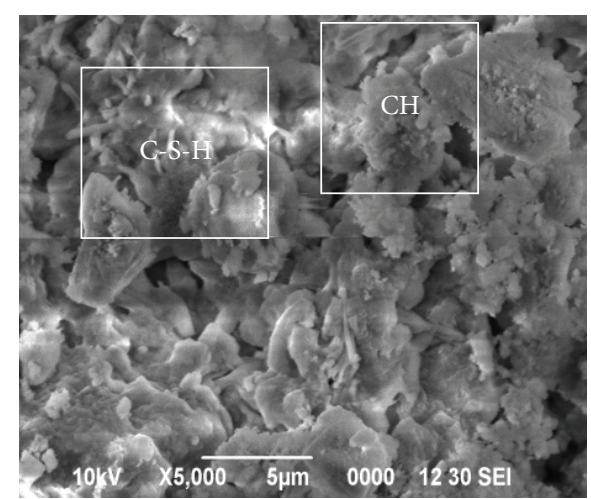

(b) $5 \% \mathrm{NS}$

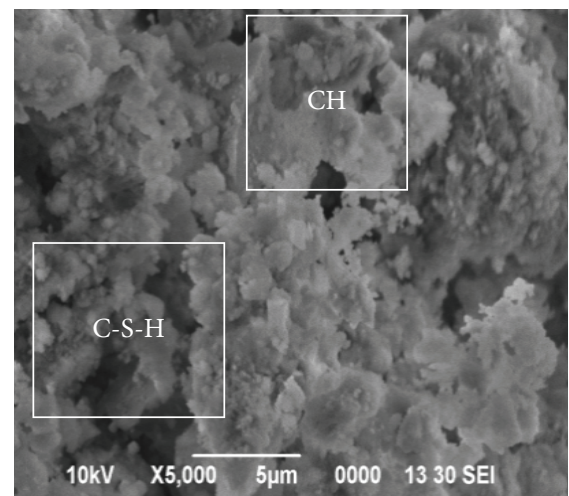

(d) UCP

FIGURE 4: SEM images of (a) NPMC, (b) $5 \%$ NS, (c) 10\% MS, and (d) UCP samples on day 28.

TABLE 2: Ca/Si and Si/Ca ratios obtained from EDS spectra.

\begin{tabular}{lcccc}
\hline Samples & NPMC & $5 \%$ NS & $10 \%$ MS & UCP \\
\hline $\mathrm{Ca} / \mathrm{Si}$ & 0.28 & 2.76 & 1.37 & 3.51 \\
\hline $\mathrm{Si} / \mathrm{Ca}$ & 3.57 & 0.36 & 0.73 & 0.28 \\
\hline
\end{tabular}

in OPC is about $1.5-1.8$, but reduced ratios are observed when pozzolans are used [16]. The surface charge on C-S-H depends on its $\mathrm{Ca} / \mathrm{Si}$ ratio: when the $\mathrm{Ca} / \mathrm{Si}$ ratio is high, the surface charge of C-S-H is positive and anions are adsorbed on the C-S-H fibers (but not cations as $\mathrm{Na}^{+}$and $\mathrm{K}^{+}$, which remain in the pore solution); when the $\mathrm{Ca} / \mathrm{Si}$ ratio is lower than about $1.2-1.3$, the surface charge of $\mathrm{C}-\mathrm{S}-\mathrm{H}$ becomes negative and alkali cations are incorporated on the C-S-H [17-19]. The Si/Ca ratio is somewhat variable but typically approximately $0.45-0.50$ in hydrated Portland cement but up to perhaps about 0.6 if slag, fly ash, or microsilica is present, depending on the proportions. $\mathrm{CH}$ is formed mainly from alite hydration [17]. Since alite has a $\mathrm{Ca} / \mathrm{Si}$ ratio of 3 to 1 and $\mathrm{C}-\mathrm{S}-\mathrm{H}$ has a $\mathrm{Ca} / \mathrm{Si}$ ratio of approximately $1.5-1.8$ to 1 , therefore $\mathrm{CH}$ is produced from the additional $\mathrm{CaO}$. Results clearly show the evidence of C-S-H and $\mathrm{CH}$ for all samples which complemented FTIR results.

3.1.4. Scanning Electron Microscope (SEM). Scanning electron microscope (SEM) morphological analysis was used to further corroborate and substantiate the results from XRD and EDS. Since $\mathrm{CH}$ and $\mathrm{C}-\mathrm{S}-\mathrm{H}$ are the components of pozzolanic reaction, SEM images shown in Figure 4 focus on the presence of $\mathrm{CH}$ and $\mathrm{C}-\mathrm{S}-\mathrm{H}$ in the three critical samples mentioned previously. From SEM images $\mathrm{CH}$ crystals solid hexagonal platelike morphology and abundant presence of $\mathrm{C}-\mathrm{S}-\mathrm{H}$ flowery-like morphology are found in the sample as it is the by-product from the cement hydration [5]. It is also observed in Figure 4(a) that evidence of pozzolanic interaction between $\mathrm{CH}$ and NPMC produces abundant presence of C-S-H flowery-like morphology. On the other hand the presence of unreacted $\mathrm{CH}$ manifested in Figures 4(b), 4(c), and 4(d) indicates lesser pozzolanic interaction. These results correlated with XRD, EDS, and previous studies that confirmed the improvement of mortar that contains MS and NS manifested in reduced porosity and increased durability. The microstructural improvement contributes to the densification of interfacial transition zone and lesser porosity of the matrix is due to the consumption of and the reduction in the amount of $\mathrm{CH}$ due to pozzolanic reaction by MS and NS particles to form C-S-H as additional cementitious material [20].

\subsection{Mechanical Property}

3.2.1. Compressive Strength Test. Figure 5 illustrates the compressive strength results for NPMC, 5\% NS, and 10\% MS 


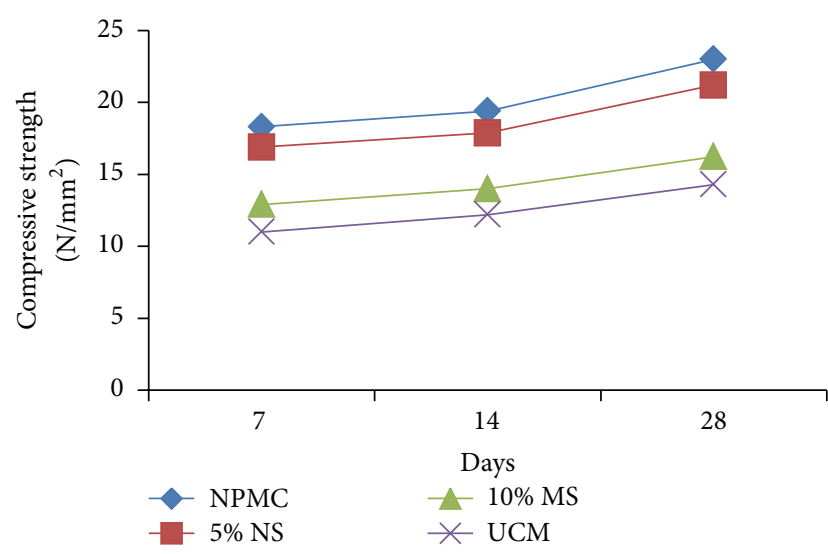

FIGURE 5: Compressive strength for NPMC, NS, MS, and UCM samples.

samples in comparison to UCM sample as a function of hydration time. All mortar samples show the normal trend for hydrating mortar [5]. NPMC has improved UCM compressive strength by $60.84 \%$. Meanwhile, $5 \%$ NS and $10 \%$ MS have $48.3 \%$ and $13.45 \%$ of UCM strength, respectively. NPCM has the highest strength among all samples on day 28 . This improvement is due to the amplified pozzolanic reactivity of both NS and MS that produce extra C-S-H gel that makes finer hydrated phases and densified microstructure matrix that compensates the agglomeration effect of MS $[4-6,8]$. These effects may enhance the durability of concrete elements and structures. Results confirmed the findings from XRD, FTIR, EDS, and SEM by displaying the highest compressive strengths of NPMC sample.

\section{Conclusion}

It can be concluded that the optimum dosage for MS and NS as cement replacement in cement paste is $10 \%$ and $5 \%$, respectively. This is due to the highest intensity in C-S-H from the XRD characterization in both samples which indicated that more C-S-H gel was produced by the addition of $10 \%$ MS and 5\% NS. FTIR and EDS analysis on NPMC sample showed evidence of NS-MS interaction with the evidence of decrease in $\mathrm{CH}$ and increase in $\mathrm{C}-\mathrm{S}-\mathrm{H}$ indicated by $\mathrm{Si} / \mathrm{Ca}$ and $\mathrm{Ca} / \mathrm{Si}$ ratios. Furthermore, morphology from SEM images also reveals the same evidence of the combinative effects of MS and NS. The mechanical properties of NPMC in terms of compressive strength were improved by $60.8 \%$ that substantiated XRD characterization, FTIR analysis, EDS analysis, and SEM morphology results. The results in this study indicate the possibility of using NS to further improve MS modified mortar and cement based product properties. Further indepth analysis and understanding on the behaviour of NPMC by using other characterization techniques are needed.

\section{Conflict of Interests}

The authors declare that there is no conflict of interests regarding the publication of this paper.

\section{Acknowledgments}

The authors wish to acknowledge the Ministry of Education and University Malaysia Sarawak for supporting this work under ERGS/TK04(02)/1011/2013(08) and RACE/c(1)/ 1108/2013(16) Grants.

\section{References}

[1] Research and Markets: Malaysia Cement Industry, 2012, http:// www.businesswire.com/news/home/20120809005630/en/Research-Markets-Malaysia-Cement-Industry-1H12.

[2] U. Hashim, E. Nadia, and S. Salleh, "Nano technology development status in malaysia:industrialization strategy and practices," International Journal of Nanoelectronic and Material, vol. 2, no. 1, pp. 119-134, 2009.

[3] J. M. R. Dotto, A. G. de Abreu, D. C. C. dal Molin, and I. L. Müller, "Influence of silica fume addition on concretes physical properties and on corrosion behaviour of reinforcement bars," Cement \& Concrete Composites, vol. 26, no. 1, pp. 31-39, 2004.

[4] A. Behnood and H. Ziari, "Effects of silica fume addition and water to cement ratio on the properties of high-strength concrete after exposure to high temperatures," Cement \& Concrete Composites, vol. 30, no. 2, pp. 106-112, 2008.

[5] V. M. Malhotra and P. K. Mehta, Pozzolanic and Cementitious Materials, Advances in Concrete Technology, Taylor \& Francis, London, UK, 2004.

[6] L. Raki, J. Beaudoin, R. Alizadeh, J. Makar, and T. Sato, "Cement and concrete nanoscience and nanotechnology," Materials, vol. 3, no. 2, pp. 918-942, 2010.

[7] R. Olar, Nanomaterials and Nanotechnologies for Civil Engineering, Din Iaşitomul Liv (Lviii), Fasc. 4, Buletinul Institutului Politehnic Din Iaşi Publicat De Universitatea Tehnică "Gheorghe Asachi”, Iași, Romania, 2011.

[8] G. Quercia and H. J. H. Brouwers, "Application of nano-silica $(\mathrm{nS})$ in concrete mixtures," in Proceedings of the 8th FIB PhD Symposium in Kgs, Lyngby, Denmark, June 2010.

[9] K. Sobolev, I. Flores, R. Hermosillo, and L. M. Torres-Martinez, "Nanomaterials and nanotechnology for high-performance cement composites," ACI Materials Journal, vol. 254, pp. 93-120, 2008, SP-254-8.

[10] K. Sobolev and M. F. Gutierrez, How Nanotechnology Can Change the Concrete World, Part I and II, American Ceramic Society Bulletin, 2005.

[11] K. Sobolev and S. P. Shah, Nanotechnology of Concrete: Recent Developments and Future Perspectives, American Concrete Institute (ACI), Farmington Hills, Mich, USA, 2008.

[12] K. Sobolev, I. Flores, L. M. Torres-Martinez, P. L. Valdez, E. Zarazua, and E. L. Cuellar, "Engineering of $\mathrm{SiO}_{2}$ nanoparticles for optimal performance in nano cement-based materials," in Nanotechnology in Construction 3: Proceedings of the NICOM3, pp. 139-148, Springer, Berlin, Germany, 2009.

[13] J. R. Houston, R. S. Maxwell, and S. A. Carroll, "Transformation of meta-stable calcium silicate hydrates to tobermorite: reaction kinetics and molecular structure from XRD and NMR spectroscopy," Geochemical Transactions, vol. 10, article 1, pp. 1-14, 2009.

[14] P. Barnes and J. Bensted, Structure and Performance of Cements, Taylor \& Francis, New York, NY, USA, 2008.

[15] F. S. Shirazi, M. Mehrali, A. A. Oshkour, H. S. C. Metselaar, N. A. Kadri, and N. A. Abu Osman, "Mechanical and physical 
properties of calcium silicate/alumina composite for biomedical engineering applications," Journal of the Mechanical Behavior of Biomedical Materials, vol. 30, pp. 168-175, 2014.

[16] F. S. Shirazi, E. Moghaddam, M. Mehrali et al., "In vitro characterization and mechanical properties of $\beta$-calcium silicate/POC composite as a bone fixation device," Journal of Biomedical Materials Research Part A, vol. 102, no. 11, pp. 3973-3985, 2014.

[17] J. J. Chen, J. J. Thomas, H. F. W. Taylor, and H. M. Jennings, "Solubility and structure of calcium silicate hydrate," Cement and Concrete Research, vol. 34, no. 9, pp. 1499-1519, 2004.

[18] E. Traversa, Nanotechnology (General)-216th ECS Meeting, vol. 25, The Electrochemical Society, 2010.

[19] H. A. Toutanji and T. El-Korchi, "The influence of silica fume on the compressive strength of cement paste and mortar," Cement and Concrete Research, vol. 25, no. 7, pp. 1591-1602, 1995.

[20] G. Quercia, G. Hüsken, and H. J. H. Brouwers, "Water demand of amorphous nano silica and its impact on the workability of cement paste," Cement and Concrete Research, vol. 42, no. 2, pp. 344-357, 2012. 

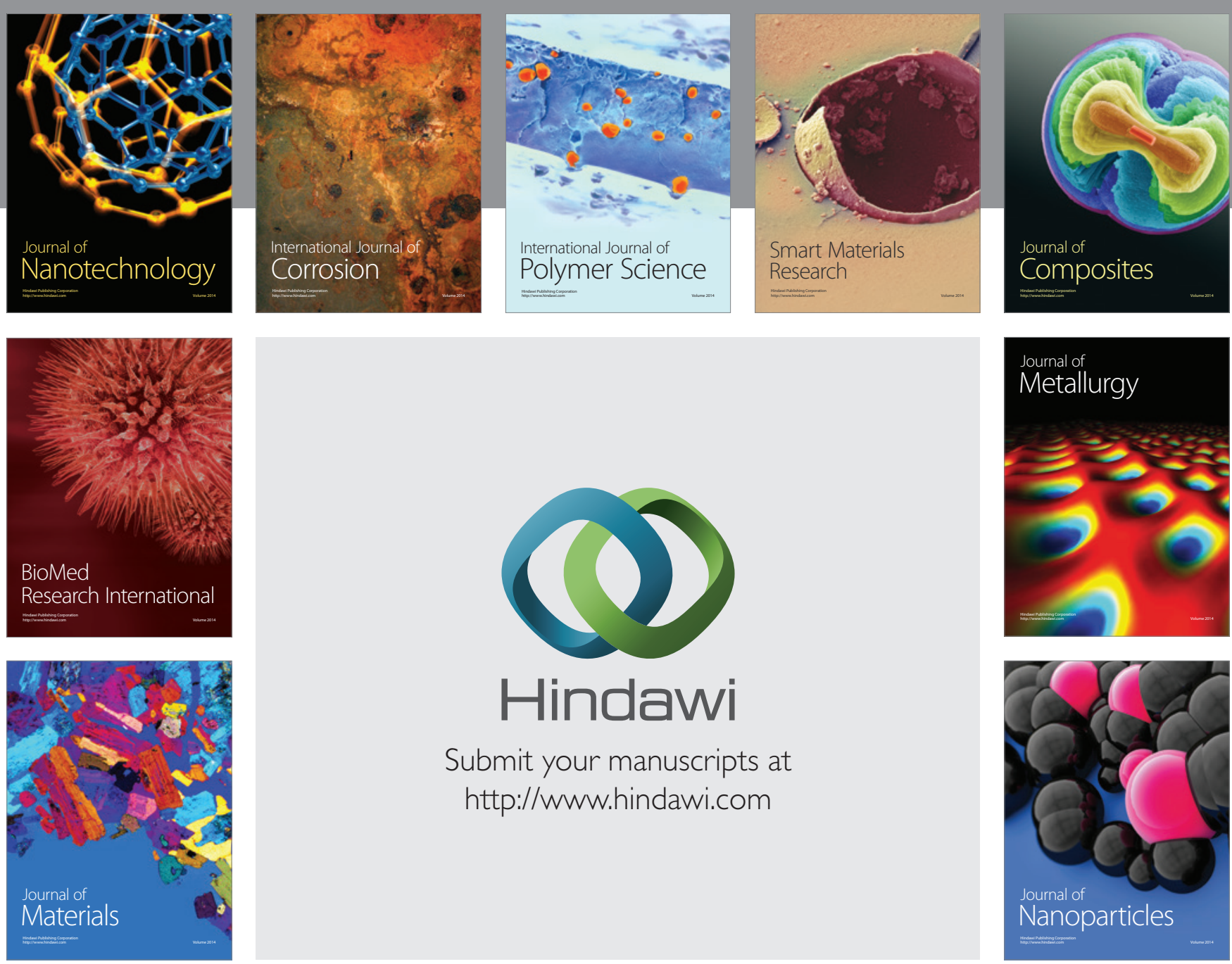

Submit your manuscripts at http://www.hindawi.com
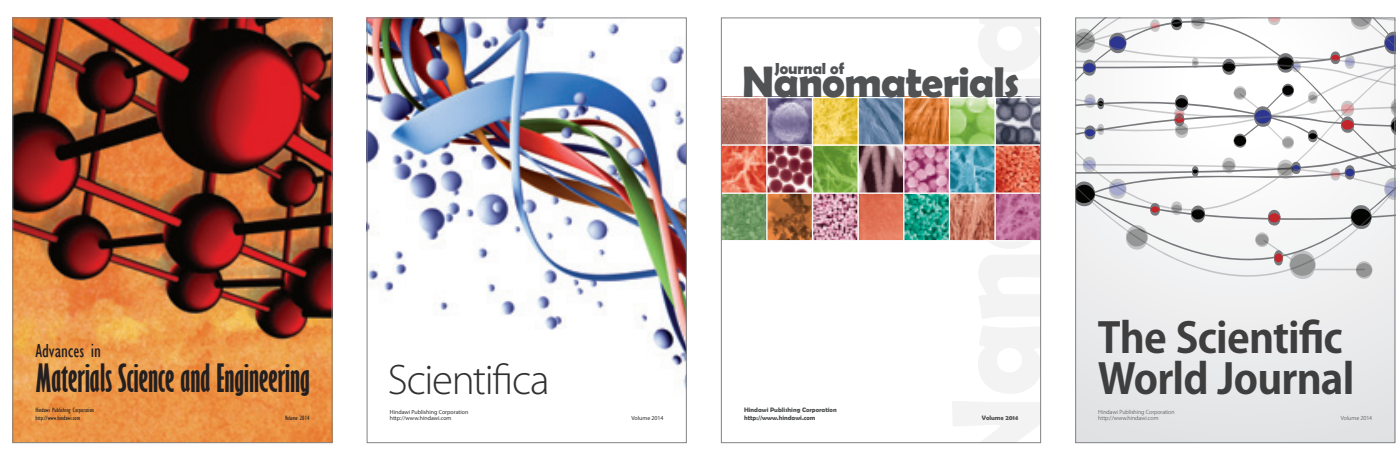

\section{The Scientific World Journal}
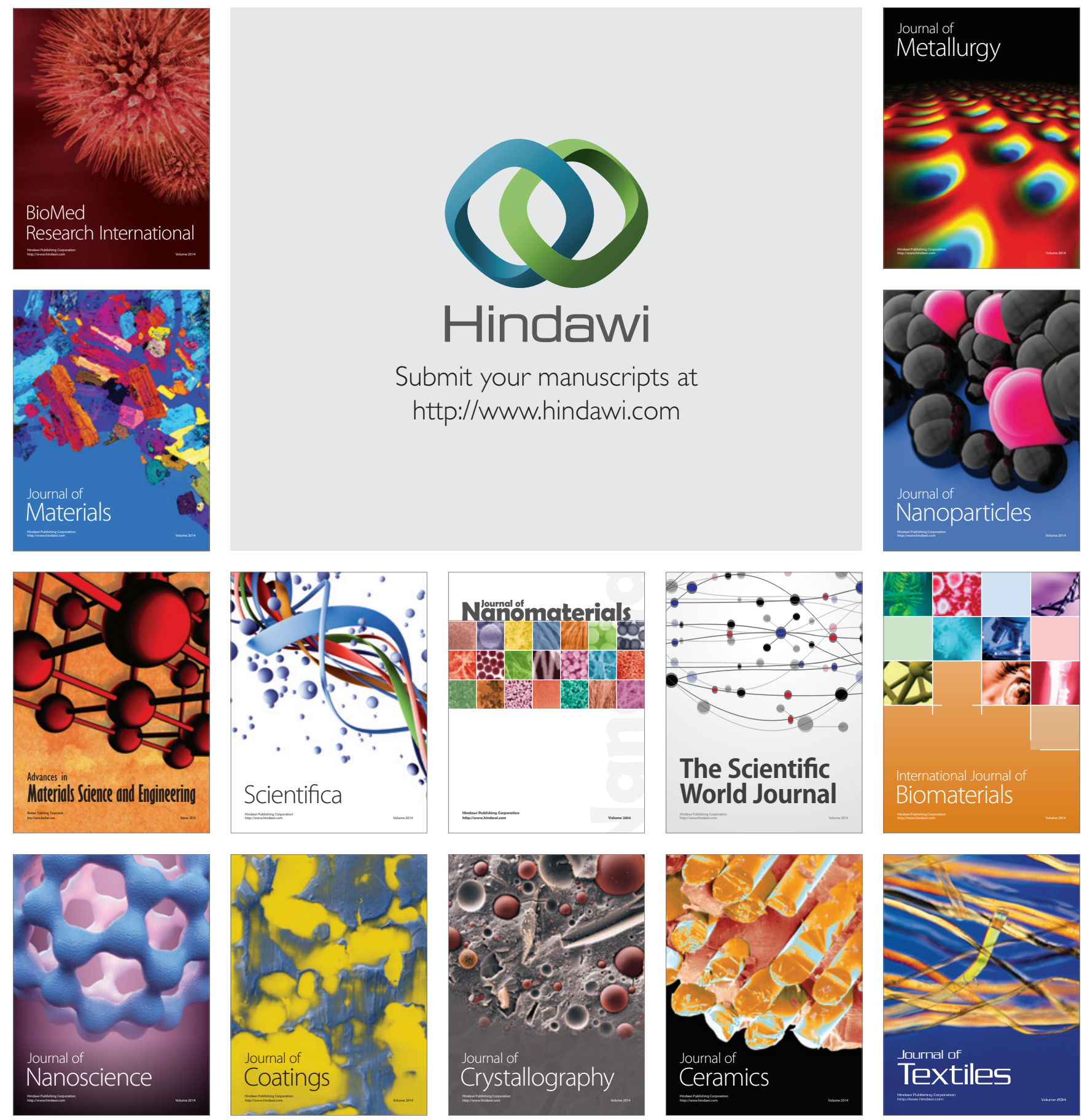